\title{
Tapered-Rib Adiabatic-Following Fiber Coupler
}

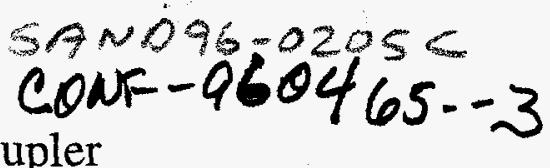

R. E. Smith, G. A. Vawter, G. R. Hadley, C. T. Sullivan, J. R. Wendt, B. Snipes, J. F. and Klem

Sandia National Laboratories

Albuquerque, NM 87185-0603

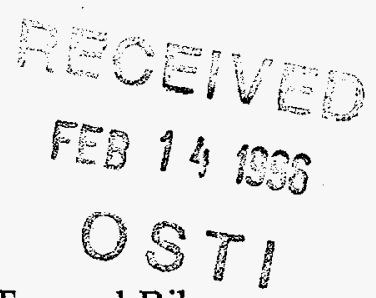

Abstract - We present the design and experimental verification of a Tapered-Rib Adiabatic-Following Fiber Coupler (TRAFFiC). This device is a monolithically integratable structure fabricated in AlGaAs designed to increase the coupling efficiency of conventional optical fibers to tightly confined semiconductor waveguide devices. This approach offers the possibility of significantly reducing fiber butt coupling losses from the typical values of 7 to $10 \mathrm{~dB}$ to values of 0.5 to $3 \mathrm{~dB}$. This long-standing packaging problem is one of the major impediments to the widespread acceptance of semiconductor-based optoelectronics. Moreover, the design can be implemented with minimal increase in fabrication complexity since it uses only epitaxial growth, lithography and etching.

The absence of an efficient and low cost means of connecting optical fibers to semiconductor waveguide devices, e.g. diode lasers and Photonic Integrated Circuits (PICs), currently poses one of the largest barriers to wide scale commercialization of semiconductor optoelectronic devices. This problem arises because of the small size of semiconductor waveguides compared to optical fibers. The 1-2 $\mu$ m elliptical modal spot of typical semiconductor waveguides is neither well-sized nor shaped to match to the standard $8 \mu \mathrm{m}$ circular modal spot of conventional single mode optical fibers. Directly coupling light from a fiber to the small waveguide typically results in 7 to $10 \mathrm{~dB}$ insertion loss. Non-integrated solutions that improve this coupling, often increase coupling at the cost of tight alignment requirements $(<1 \mu \mathrm{m})$ and are thus prohibitively expensive.

Recently several groups have presented devices that address this problem with a variety of monolithic approaches. An excellent survey of these is provided by Ref. 1. Our designs, shown in Fig. 1, are essentially Shani-Henry couplers, ${ }^{2}$ similar to that discussed in Ref. 3, but with several modifications to increase performance and process tolerance.

Many tapered mode converters of this type require very sharp taper points, and the rounding of these points increases the losses substantially. We have avoided this potential process intolerant problem in our device designs. Figs. 2 shows the effect of a finite taper width on the overlap of the conventional fiber mode with the mesa mode. Notice that coupling losses are low and constant for taper end widths less than $1.8 \mu \mathrm{m}$. 


\section{DISCLAIMIER}

Portions of this document may be illegible in electronic image products. Images are produced from the best available original document. 
The major theoretical source of loss in our designs are caused by stair-stepping brought about by pixelization in the lithographic processes. This effect is shown in Fig. 3 . It is worth pointing out that the excess loss due to pixelization can be minimized in the design process and that it scales linearly with pixel size.

We have fabricated and tested devices exhibiting losses of approximately 2-3 dB ( $0.5 \mathrm{~dB}$ to mesa overlap loss $+0.8 \mathrm{~dB}$ excess taper loss $+\sim 1.2 \mathrm{~dB}$ estimated material/ waveguide loss). The devices currently being fabricated incorporate lower-loss waveguide designs, have improved coupling to fiber and excess pixelization taper loss. These devices have predicted fiber-to-waveguide coupling losses to $0.9 \mathrm{~dB}$ ( $0.2 \mathrm{~dB}$ fiber to mesa overlap loss +0.5 excess taper loss $+0.2 \mathrm{~dB}$ estimated material/waveguide loss). Furthermore, for these new designs a $\pm 10 \%$ variation in our most critical processing dimension brings about a variation of only $\pm 0.15 \mathrm{~dB}$ respectively.
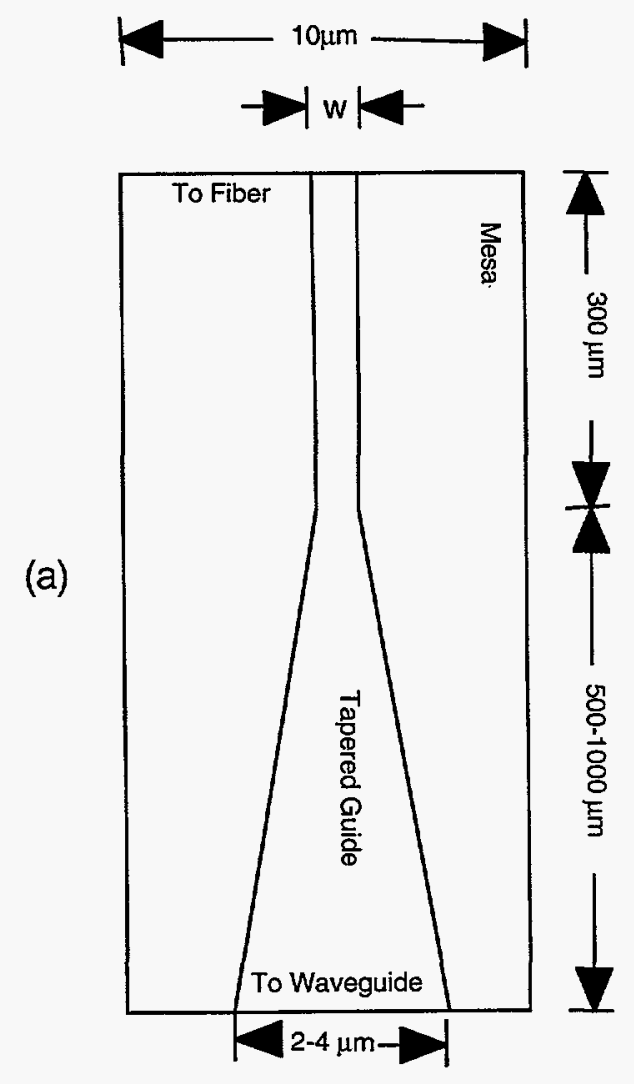

(b)

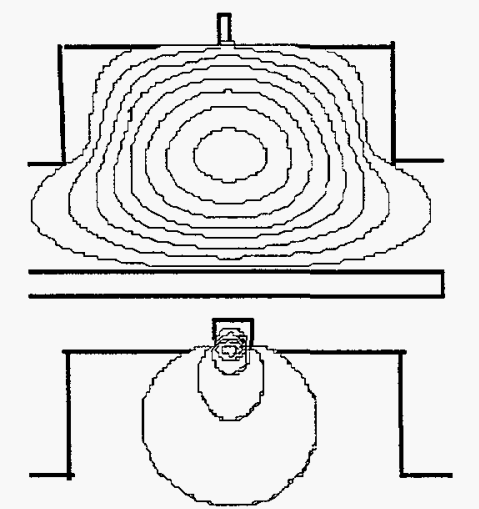

(c)

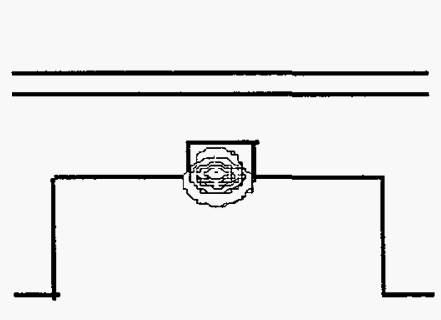

(d)

Fig. 1 A schematic representation of the (TRAFFiC) device. (a) Top View. (b) A cross section showing the mesa mode, which is the fundamental mode of the device for rib widths $<1.8 \mu \mathrm{m}$ for the device discussed in Fig. 2-3. (c) A cross section showing the fundamental mode in transition from the mesa to the rib. This transition occurs at rib widths of 1.8-2.1 $\mu \mathrm{m}$. (d) A cross section showing the fundamental mode confined to the rib, widths of greater than $2.1 \mu \mathrm{m}$. 


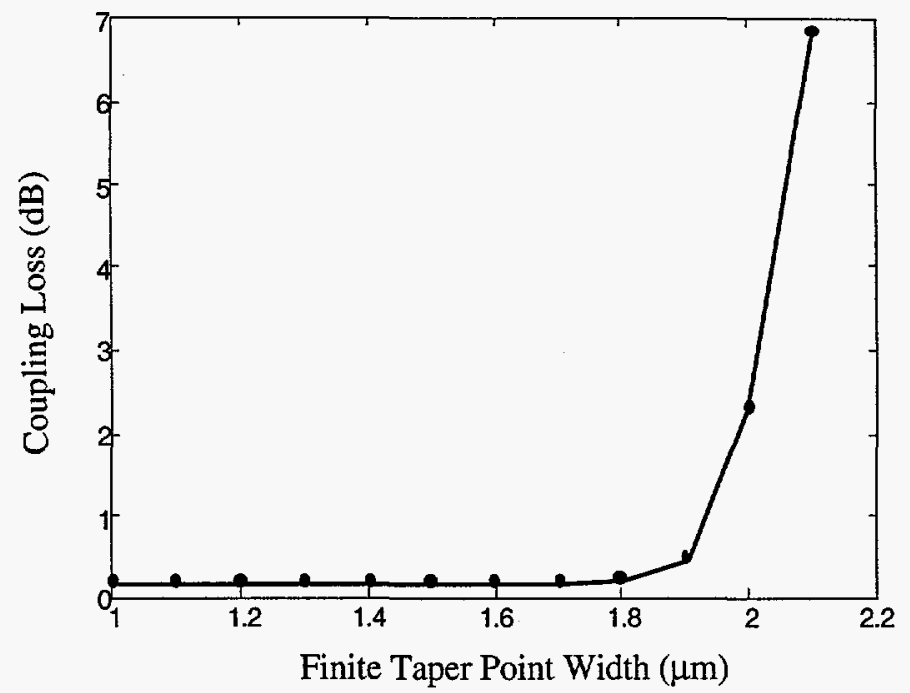

Fig. 2 The effect of finite taper point width on fiber-to-mesa waveguide coupling. For all rib waveguide widths less than $1.8 \mu \mathrm{m}$ the fundamental mode is confined to the mesa where it has good overlap with conventional fiber.

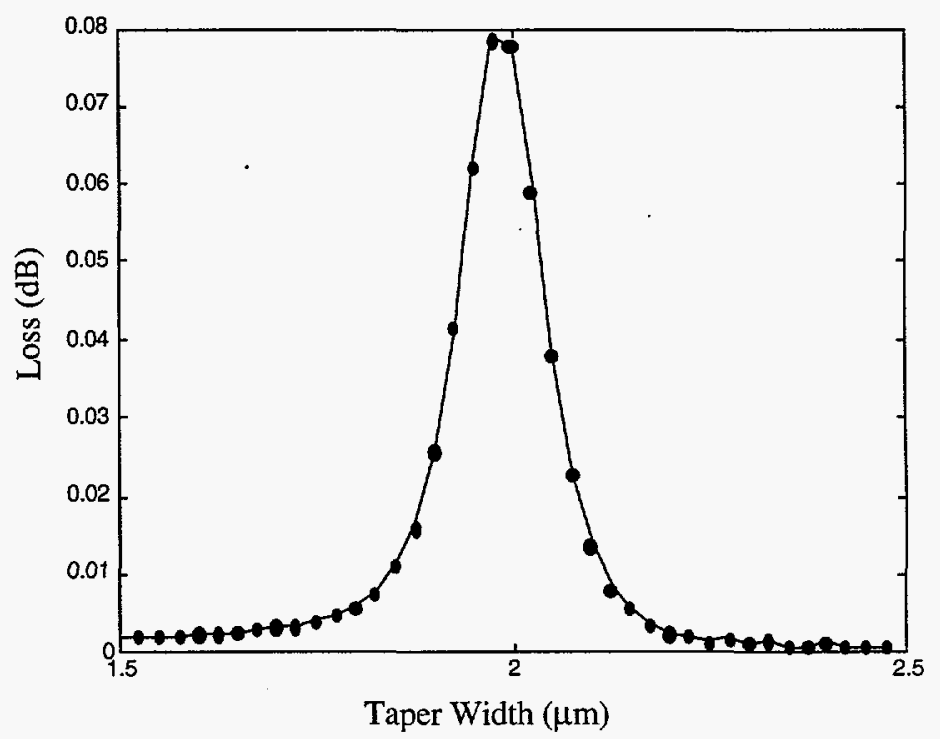

Fig. 3 Excess taper loss at each pixel step. The lateral tapering of the upper rib waveguide is comprised of a series of discrete steps. The size of the steps is defined by the pixel size of the lithographic mask. This figure shows the loss associated with each of the $(0.025$ $\mu \mathrm{m})$ steps. The sum of these individual losses sets a lower bound on the excess taper loss.

[1] LEOS, IEEE Laser and Electro-Optics Society 1995 meeting, Vol 1,EMGW1-2.

[2] Y. Shani, C. H. Henery, R. C. Kristler, K. J Orlowsky, and Ackerman, Phys. Lett. 55. pp 2389-2391,1989.

[3] R.N. Thurston, Eli Kapon and Arie Shahar, Opt. Lett., vol. 16, pp.306-308, 1991.

This work was supported by the United States Department of Energy under Contract DEAC04-94AL85000. 


\section{DISCLAIMER}

This report was prepared as an account of work sponsored by an agency of the United States Government. Neither the United States Government nor any agency thereof, nor any of their employees, makes any warranty, express or implied, or assumes any legal liability or responsibility for the accuracy, completeness, or usefulness of any information, apparatus, product, or process disclosed, or represents that its use would not infringe privately owned rights. Reference herein to any specific commercial product, process, or service by trade name, trademark, manufacturer, or otherwise does not necessarily constitute or imply its endorsement, recommendation, or favoring by the United States Government or any agency thereof. The views and opinions of authors expressed herein do not necessarily state or reflect those of the United States Government or any agency thereof. 